\title{
Mechanical Properties and Microcosmic Properties of Self-Compacting Concrete Modified by Compound Admixtures
}

\author{
Song Yang ${ }^{1}$, Bing $\mathrm{Qi}^{1}$, Zubin $\mathrm{Ai}^{1}$, Zhensheng $\mathrm{Cao}^{1}$, Shiqin $\mathrm{He}^{2, *}$ and Lijun $\mathrm{Li}^{3}$ \\ ${ }^{1}$ Power China Roadbridge Group Co., Ltd., Beijing, 100048, China \\ ${ }^{2}$ College of Civil Engineering, North China University of Technology, Beijing, 100043, China \\ ${ }^{3}$ Sichuan Tieke New Building Materials Co., Ltd., Chengdu, 610000, China \\ ${ }^{*}$ Corresponding Author: Shiqin He. Email: ibdv61@163.com \\ Received: 15 March 2021 Accepted: 29 April 2021
}

\begin{abstract}
It has become a research hotspot to explore raw material substitutes of concrete. It is important to research the mechanical properties of self-compacting concrete (SCC) with slag powder (SP) and rubber particle (RP) replacing cement and coarse aggregate, respectively. 12 kinds of composite modified self-compacting concrete (CMSCC) specimens were prepared by using $10 \%, 20 \%$ and $30 \%$ SP and $30 \%, 40 \%, 50 \%$ and $60 \%$ RP. The rheological properties, mechanical properties and microstructure of the CMSCC were investigated. Results indicate that the workability, compressive strength, splitting tensile strength and flexural strength of CMSCC prepared by $20 \%$ SP and less than $40 \%$ RP are improved. In order to maximize the utilization of waste materials, $20 \%$ SP and $40 \%$ RP can be used as the optimal ratio of the combined modifier. The microstructure shows that the addition of proper amount of SP is conducive to the formation of increasingly more uniform C-S-H gel. C-S$\mathrm{H}$ gel can fill the internal pores of the sample and enhance the adhesion between the aggregate, thus improving the mechanical properties of CMSCC. RP has a rougher surface and lower density and stiffness, which inhibits the workability and mechanical properties of CMSCC. The above research results have important theoretical and practical significance for the selection of raw materials of self-compacting concrete and the rational use of industrial wastes.
\end{abstract}

\section{KEYWORDS}

Self-compacting concrete; slag powder; rubber particle; mechanical properties; microstructure

\section{Introduction}

Self-compacting concrete (SCC) is a new type of concrete material with high mobility. SCC simplifies the construction process, greatly saves the labor cost, reduces the power consumption and noise pollution caused by vibration, and has been widely used [1,2]. Compared with ordinary concrete, the most important characteristic of SCC is its excellent working performance through the high dosage of cementitious material (cement). Cement industry is a highly polluting and energy-consuming industry. The production process not only consumes a large amount of coal, limestone, iron ore and clay, but also emits a large amount of $\mathrm{CO}_{2}$, which seriously pollutes the environment [3,4]. In addition, the massive 
exploitation of concrete natural aggregate also causes a series of environmental problems. The large-scale use of concrete material poses a severe challenge to the supply of concrete raw materials $[5,6]$.

With the acceleration of industrialization, a large number of industrial wastes, such as fly ash, slag powder, tailings and waste rubber, are seriously endangering the ecological environment [7,8]. The application of these harmful substances in the production of building materials can not only solve the problem of environmental pollution, but also reduce the production cost of building materials, so it has been widely concerned. Mahdi et al. [9] studied the durability and environmental harmfulness of concrete after fly ash replaced cement and base ash replaced river sand, and concluded that fly ash and base ash could partially replace the raw material of concrete. Hai et al. [10] prepared SCC containing fly ash to replace part of cement, and further explored the influence of steel fiber on the performance of fly ash modified SCC. The results showed that the addition of steel fiber could significantly improve the axial compression deformation ability of fly ash SCC, but had little effect on the compressive strength of fly ash modified SCC. Soliman et al. [11,12] found in their study that when the replacement proportion of glass powder was $20 \%$, the compressive strength of concrete increased by about $6 \%$, and when the replacement proportion continued to increase, the compressive strength of concrete gradually decreased. Ismail et al. $[13,14]$ showed that when the amount of cementing material was $500 \mathrm{~kg} / \mathrm{m}^{3}$, concrete with $15 \%$ rubber content had acceptable strength, fluidity and stability. When the dosage of cementitious material is $550 \mathrm{~kg} / \mathrm{m}^{3}$, the stability of rubber concrete can be improved, and the rubber content can reach $20 \%$ at most. In addition, the incorporation of fly ash can improve the working performance of rubber concrete and reduce the amount of efficient water reducer $[15,16]$. Therefore, industrial waste can be used effectively as a substitute for cementitious materials in concrete.

In addition to studying the possibility of replacing cementitious materials in concrete, a large number of researchers have focused on the feasibility of replacing aggregate in concrete with industrial waste. Eldin et al. found through experimental study that when concrete fine aggregate was completely replaced by rubber aggregate, the compressive strength and tensile strength of concrete were reduced by $65 \%$ and $50 \%$, respectively [17]. Bompa et al. [18] established the fractional relationship between the strength reduction coefficient of rubber aggregate concrete and the volume replacement rate of rubber aggregate by using mathematical regression method based on the experimental data collected by different scholars. Other studies have shown that the shape, grading, hydration degree and water content of concrete coarse aggregate have a profound impact on the physical and mechanical properties of concrete [19,20]. Abdallah et al. [21,22] observed that replacing coarse aggregate with high-angle glass particles would reduce the workability of concrete. It can be seen that the coarse aggregate also plays an important role in the performance of concrete.

However, most scholars focus on the study of the influence of single admixtures on SCC performance, and there are relatively few studies on the influence of compound admixtures on SCC performance, especially the study on the modification mechanism of SCC by a variety of industrial wastes. Therefore, in this paper, cement and coarse aggregate in SCC were replaced by SP and RP respectively to prepare CMSCC. By studying the basic physical and mechanical properties and microscopic characteristics of CMSCC, the engineering application value and composite modification mechanism of CMSCC were obtained.

\section{Raw Materials and Test Methods}

\subsection{Materials}

The raw materials of CMSCC are as follows: (1) P.O 42.5 ordinary Portland cement (OPC) with an apparent density of $3100 \mathrm{~kg} / \mathrm{m}^{3}$; (2) The specific surface area and activity index of granular blast furnace slag powder are $4200 \mathrm{~cm}^{2} / \mathrm{g}$ and 105 , respectively. (3) Fine aggregate with particle size less than $2.30 \mathrm{~mm}$ have an apparent density of $2600 \mathrm{~g} / \mathrm{cm}^{3}$, water content of $1.2 \%$, and fineness modulus of 2.55 . 
(4) Coarse aggregate with particle size between 4.70 and $10 \mathrm{~mm}$ have an apparent density of $2600 \mathrm{~g} / \mathrm{cm}^{3}$ and water content of $0.3 \%$. (5) Polycarboxylic superplasticizer (PS) have a solid content of $16.5 \%$ and water reduction rate of $25.5 \%$. (6) RP with a particle size of $6 \sim 10 \mathrm{~mm}$. (7) Water. Chemical compositions of SP and cement are summarized in Table 1. SP and RP used in the research are shown in Fig. 1.

Table 1: Chemical compositions of SP and cement

\begin{tabular}{lllllll}
\hline Materials & \multicolumn{5}{c}{ Mass fraction/\% } \\
\cline { 2 - 7 } & $\mathrm{CaO}$ & $\mathrm{Al}_{2} \mathrm{O}_{3}$ & $\mathrm{SO}_{3}$ & $\mathrm{SiO}_{2}$ & $\mathrm{Fe}_{2} \mathrm{O}_{3}$ & Others \\
\hline OPC & 63.27 & 5.82 & 2.62 & 19.73 & 4.35 & 4.21 \\
$\mathrm{SP}$ & 39.31 & 17.12 & 3.03 & 28.54 & 4.22 & 7.70 \\
\hline
\end{tabular}
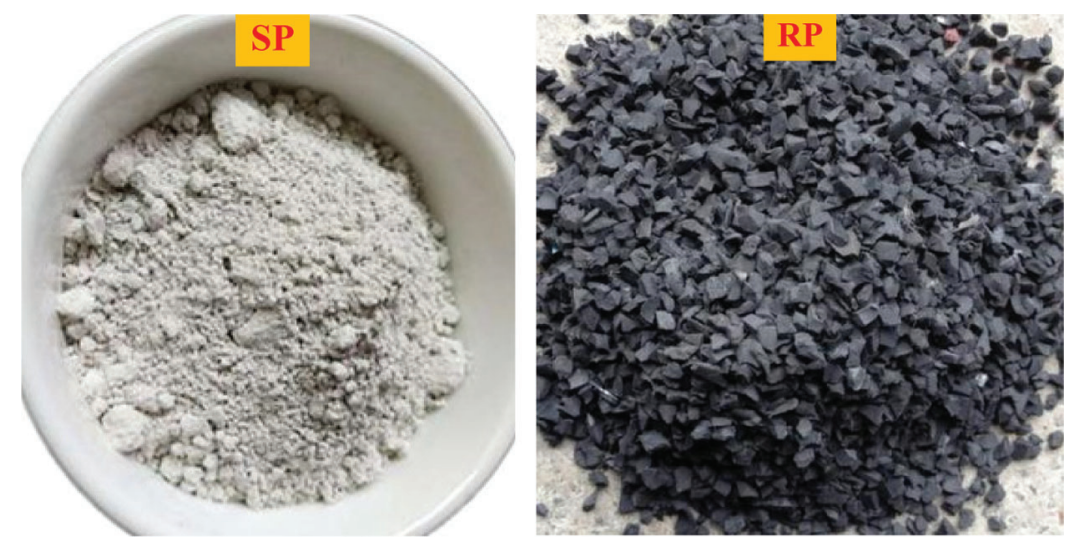

Figure 1: SP and RP

\subsection{Mixture Designs}

The fresh and hardened concrete properties of CMSCC would be investigated. The mix design in this study was modeled on the previous research results [1], and revised in accordance with the characteristics of the materials selected for this study. Standard SCC ratio without SP and RP was used as control group. A combination of twelve other mixes containing $10 \%, 20 \%$, and $30 \%$ SP as cement replacement and $30 \%, 40 \%, 50 \%$, and $60 \% \mathrm{RP}$ as coarse aggregate replacement were prepared. The material composition of the mixture is shown in Table 2.

\subsection{Test Methods}

Workability tests of fresh concrete involved slump flow test and V-funnel test performedas per ASTM and EFNARC standards [23]. The material fluidity is evaluated by the slump spread diameter D when the material stops flowing. The cohesiveness of the material was evaluated by the flow time extension up to $500 \mathrm{~mm}$ and through the V-shaped funnel. The slump flow test is conducted as shown in Fig. 2. 
Table 2: Mix design composition $/ \mathrm{kg} \cdot \mathrm{m}^{3}$

\begin{tabular}{llllllll}
\hline Mix & OPC & SP & Water & Fine aggregate & Coarse aggregate & RP & PS \\
\hline S0R0 & 450 & 0 & 300 & 980 & 710 & 0 & 15 \\
S10R30 & 405 & 45 & 300 & 980 & 497 & 213 & 15 \\
S10R40 & 405 & 45 & 300 & 980 & 426 & 284 & 15 \\
S10R50 & 405 & 45 & 300 & 980 & 355 & 355 & 15 \\
S10R60 & 405 & 45 & 300 & 980 & 284 & 426 & 15 \\
S20R30 & 360 & 90 & 300 & 980 & 497 & 213 & 15 \\
S20R40 & 360 & 90 & 300 & 980 & 426 & 284 & 15 \\
S20R50 & 360 & 90 & 300 & 980 & 355 & 355 & 15 \\
S20R60 & 360 & 90 & 300 & 980 & 284 & 426 & 15 \\
S30R30 & 315 & 135 & 300 & 980 & 497 & 213 & 15 \\
S30R40 & 315 & 135 & 300 & 980 & 426 & 284 & 15 \\
S30R50 & 315 & 135 & 300 & 980 & 355 & 355 & 15 \\
S30R60 & 315 & 135 & 300 & 980 & 284 & 426 & 15 \\
\hline
\end{tabular}

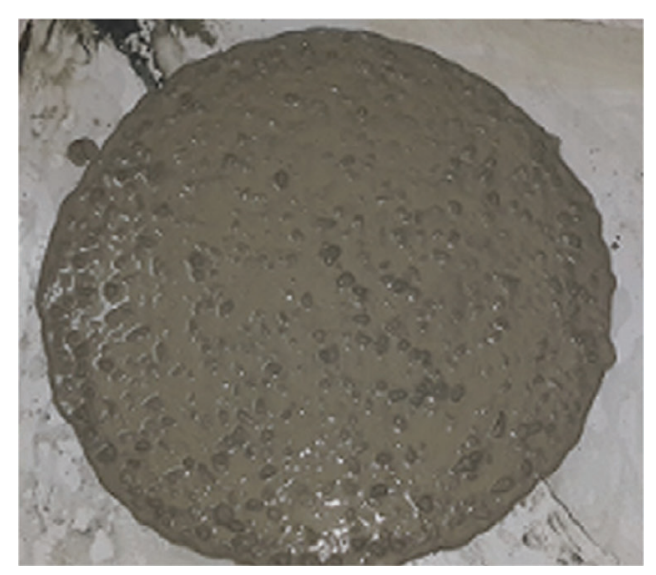

Figure 2: Slump flow test

To study the mechanical properties of CMSCC, cube specimens $100 \mathrm{~mm} \times 100 \mathrm{~mm} \times 100 \mathrm{~mm}$ and prisms specimens $100 \mathrm{~mm} \times 100 \mathrm{~mm} \times 350 \mathrm{~mm}$ were cast for each mix and cured for 7 days and 28 days in water tanks as per ASTM C192/C192M [24] after de-molding. According to ASTM C39/C39M [25] and ASTM C496/C496M [26], cube specimens with different mixing modes and cured ages of CMSCC were tested for compressive strength and splitting tensile strength. According to ASTM C78/C78M [27], prisms specimens with different mixing modes and cured ages of CMSCC were tested for flexural strength in four point bending test. All the test results are the average of the three samples. The microstructure of CMSCC with different SP and RP content was tested by SEM. And the samples were dried to a constant weight under vacuum and then tested. 


\section{Results and Discussion}

\subsection{Slump Flow Test}

The result of slump flow test is shown in Fig. 3. The slump flow of CMSCC varies from 652 to $730 \mathrm{~mm}$ with increasing SP and RP content. The slump flow of CMSCC increases first and then decreases with increasing SP content at constant level of RP. When SP content is $20 \%$, the workability of CMSCC is the best, which indicates that the replacement of cement with an appropriate amount of SP can significantly improve the fluidity of CMSCC. The activity of SP is not fully activated when the content of SP is higher than $20 \%$, and the remaining SP is filled in the pores as fine aggregate, resulting in a gradual decrease in the workability of the CMSCC. Boukendakdji et al. [28,29] pointed out that the optimal replacement amount of slag powder to improve SCC fluidity was $15 \%$, and when the slag powder amount exceeded $15 \%$, the growth trend was no longer obvious. Meanwhile, the slump flow of CMSCC decreases with increasing RP content at constant level of SP. The decrease in workability may be attributed to the rough serrated edge of RP, and more energy is needed to overcome the internal friction in the flow. As can be seen from Fig. 3, the standard SCC without SP and RP has a slump flow of $716 \mathrm{~mm}$. When SP content is $20 \%$ and RP content is no more than $40 \%$, the workability of CMSCC is better than that of standard SCC.

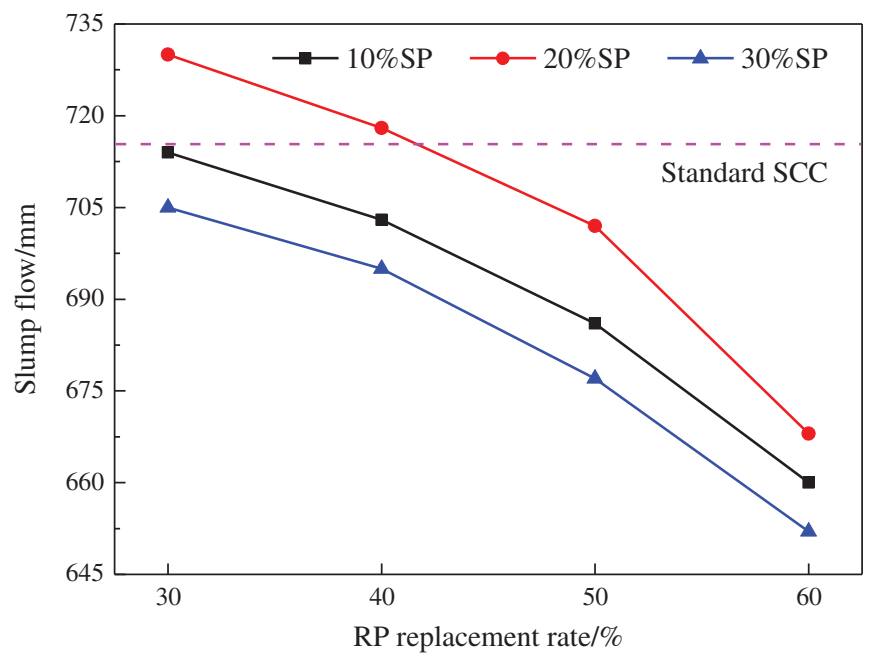

Figure 3: Slump flow variations with increasing SP and RP content

\section{$3.2 T_{500}$ and V-Funnel Time}

The results of $\mathrm{T}_{500}$ and $\mathrm{V}$-funnel time are shown in Fig. 4. The $\mathrm{T}_{500}$ time and $\mathrm{V}$-funnel time of the CMSCC mixture fluctuated in the range of $2.9 \sim 6.6 \mathrm{~s}$ and $7.8 \sim 14.5 \mathrm{~s}$, respectively. The $\mathrm{T}_{500}$ time and V-funnel time of CMSCC decreases first and then increases with increasing SP content at constant level of RP. When SP content is $20 \%$, the viscosity of CMSCC is the minimum, which indicates that the replacement of cement with an appropriate amount of SP can significantly reduce the viscosity of CMSCC. The activity of SP is not fully activated when the content of SP is higher than $20 \%$, and the remaining SP is filled in the pores as fine aggregate, resulting in a gradual increase in the viscosity of the CMSCC. Dadsetan et al. [30] also obtained similar results: when the water-binder ratio was 0.4, replacing cement with $10 \%$ slag powder would result in the maximum reduction of V-funnel flow time. Meanwhile, the $\mathrm{T}_{500}$ time and V-funnel time of CMSCC increases with increasing RP content at constant level of SP. The increase in viscosity may be attributed to the rough serrated edge of RP, and more energy is needed to overcome the internal friction in the flow. As can be seen from Fig. 3, the $\mathrm{T}_{500}$ time and V-funnel time 
of standard SCC without SP and RP are 3.4 and $8.9 \mathrm{~s}$, respectively. It can be seen from the comprehensive test results that when SP content is $10 \%$ or $20 \%$ and RP content is no higher than $40 \%$, the $\mathrm{T}_{500}$ time and Vfunnel time of CMSCC are lower than or close to the standard SCC.

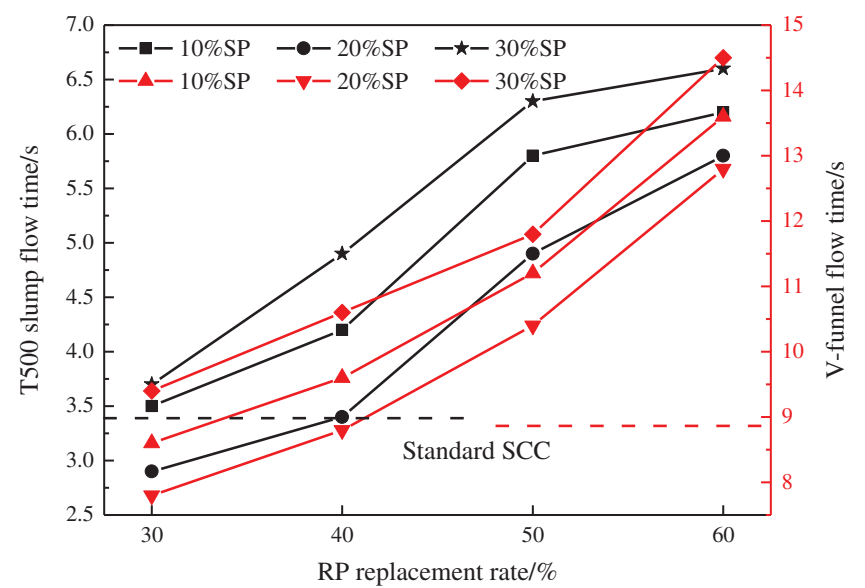

Figure 4: T500 and V-funnel time variations with increasing SP and RP content

\subsection{Compressive Strength}

The 7-day and 28-day compressive strength variation with increasing SP and RP content are graphically shown in Fig. 5. The 7-day and 28-day compressive strengths of CMSCC ranged from 29.2 to 45.8 MPa and 37.2 to $54.8 \mathrm{MPa}$, respectively. At constant level of RP content, the 7-day compressive strength of the CMSCC decreases gradually, while the 28-day compressive strength increases gradually with the increasing of SP content. The reason for the above results is that the activation of pozzolanic activity of SP takes a long time, so the early strength of CMSCC is low. When the pozzolanic activity of SP is fully activated, the strength of CMSCC will increase. When the SP content is higher than $20 \%$, the 28-day compressive strength growth rate of CMSCC is low. The enhancement effect of SP on the 28-day compressive strength of CMSCC can be attributed to two main factors: (1) SP with particle size smaller than cement can reduce the porosity of CMSCC and enhance the bonding ability between slurry and aggregate to form a dense microstructure, thus increasing the compressive strength of CMSCC. Meanwhile, SP with larger specific surface area can produce more $\mathrm{Ca}(\mathrm{OH})_{2}$ in the hydration process, which provides more reactive substances for the formation of calcium silicate hydrate gel (C-S-H). C-S-H can better fill voids and reduce the number of large pores. (2) As can be seen from Table 1, the $\mathrm{SiO}_{2}$ content in SP is higher than that in cement, which may also improve the compressive strength of CMSCC. Nazari et al. [31] pointed out that an appropriate amount of nano- $\mathrm{SiO}_{2}$ can improve the mechanical properties of SCC.

On the other hand, there are decrease in 7-day and 28-day compressive strength of CMSCC with increase in RP content at constant level of SP content. When the RP content is between $40 \%$ and $50 \%$, the compressive strength decreases most obviously. The effect of RP on CMSCC compressive strength is attributed to two main factors: (1) The cohesive force between RP and cement slurry is weak, and it is easy to form weak interfacial transition zone (ITZ). (2) The density and stiffness of RP and surrounding concrete are greatly different. When subjected to load, the deformation of RP and surrounding concrete is uneven, and cracks are more likely to occur in the weak ITZ, leading to the reduction of concrete strength. Mastali et al. [32] pointed out that an appropriate amount of SP contributes to the formation of a more compact C-S-H gel, thus enhancing the bond between RP and concrete matrix. Based on the 7-day 
and 28-day compressive strength test results of CMSCC, the strength of CMSCC with proper SP content was better than that of standard SCC when the RP content was no more than $40 \%$.
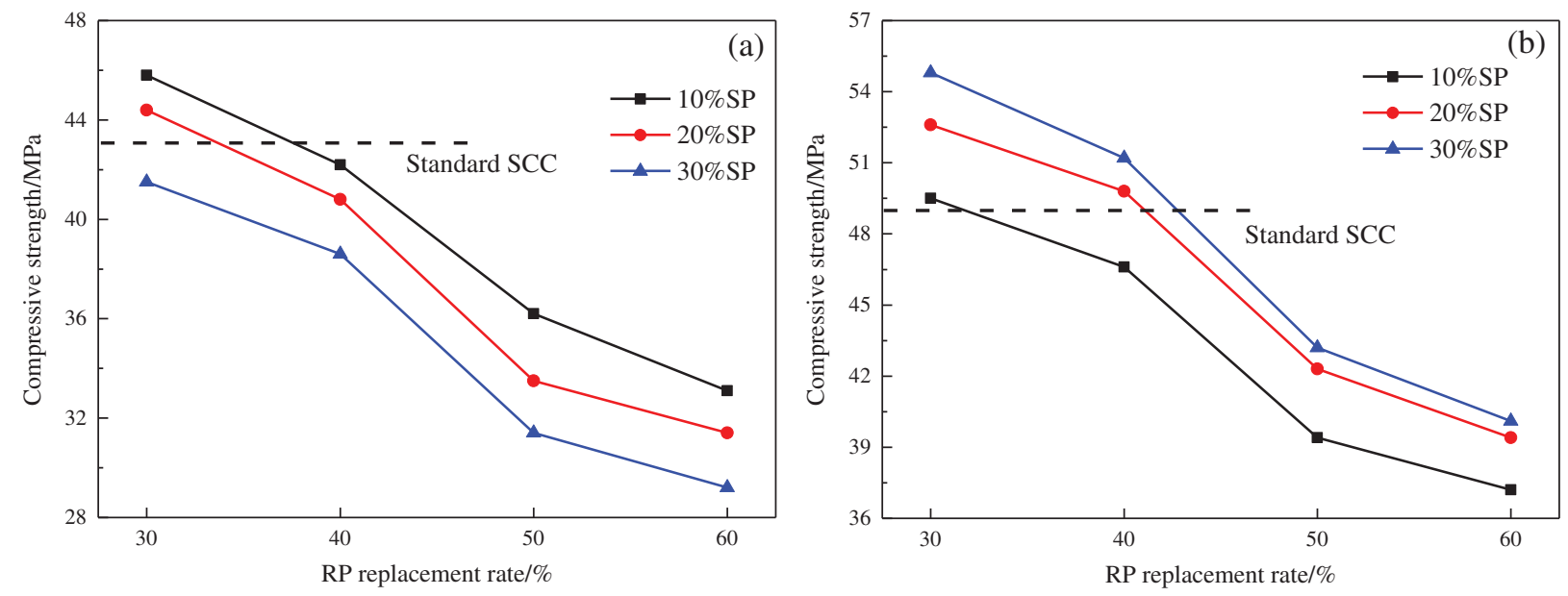

Figure 5: Result of 7-day and 28-day compressive strength. (a) 7-day; (b) 28-day

\subsection{Elastic Modulus}

The average results (three samples) pertaining to the secant elastic modulus of the CMSCC are presented in Fig. 6. As can be seen from the Fig. 6, SP contributes to the growth of the elastic modulus of CMSCC, while RP reduces the elastic modulus of CMSCC. The elastic modulus of a concrete composite is closely related to that of its aggregates [32]. Therefore, the elastic modulus of CMSCC would be significantly reduced after the replacement of aggregate by RP with weaker stiffness. The activity of SP volcanic ash can improve the elastic modulus of CMSCC to a certain extent.

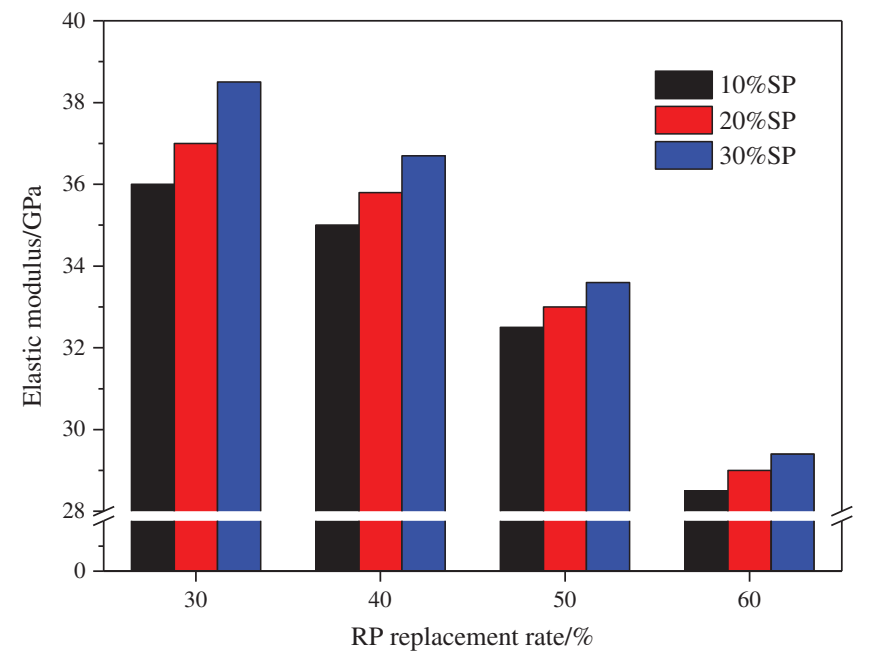

Figure 6: Result of elastic modulus

\subsection{Splitting Tensile Strength and Flexural Strength}

The splitting tensile strength and flexural strength of 7-day and 28-day variation with increasing SP and RP content are graphically shown in Figs. 7 and 8, respectively. Similar to compressive strength, the 7-day 
splitting tensile strength and flexural strength of the CMSCC decreases gradually, while the 28-day splitting tensile strength and flexural strength increases gradually with the increasing of SP content at constant level of RP content. The 28-day splitting tensile strength and 28-day flexural strength of CMSCC varied between 2.1 5.1 MPa and 3.2 7.8 MPa, respectively. Similar to 28-day compressive strength, the splitting tensile strength and flexural strength of the CMSCC increased gradually with the increase of SP content at constant level of RP content. Differently, when SP content is higher than $20 \%$, the splitting tensile strength and flexural strength of CMSCC increase more obviously at a lower RP content. This is because when the pozzolanic activity of SP is fully excited, it can better enhance cohesive force of aggregateclean slurry interface and RP-matrix interface than cement. On the other hand, as the content of RP increase, the splitting tensile strength and flexural strength of CMSCC decrease, and the enhancement effect of SP on CMSCC will also weaken. When the RP content is between $40 \%$ and $50 \%$, the tensile strength decreases most obviously. The cohesive force between RP and cement slurry is weak, and it is easy to form weak ITZ. Under the action of tensile stress, the weak ITZ rapidly forms cracks and expands, resulting in a significant decrease in the splitting tensile strength and flexural strength of the specimen. Based on the above test results, it is concluded that when the RP content is no more than $40 \%$, an appropriate amount of SP can enhance the tensile strength of CMSCC.
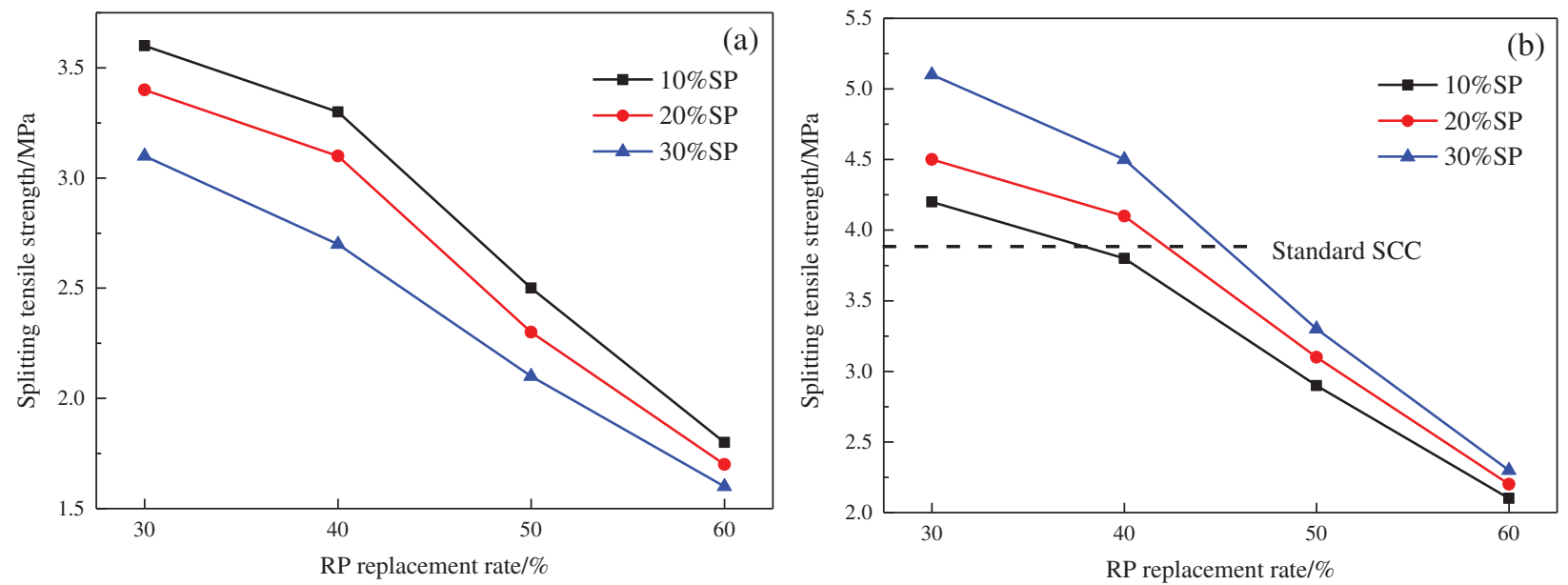

Figure 7: Results of 7-day and 28-day splitting tensile strength. (a) 7-day; (b) 28-day
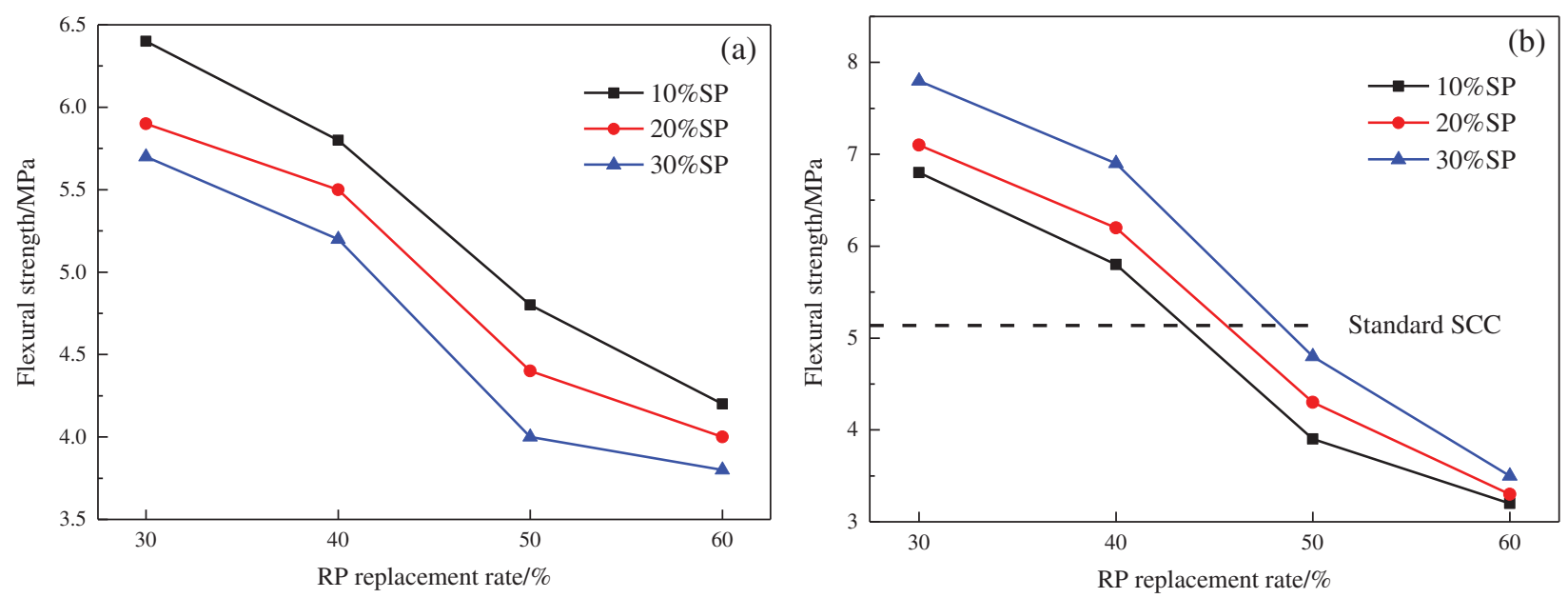

Figure 8: Results of 7-day and 28-day flexural strength. (a) 7-day; (b) 28-day 
Fig. 9 provides the typical failure modes of CMSCC after splitting tensile and flexural tests. As can be seen from the figure, CMSCC is completely divided into two fracture parts after failure, showing brittle failure.
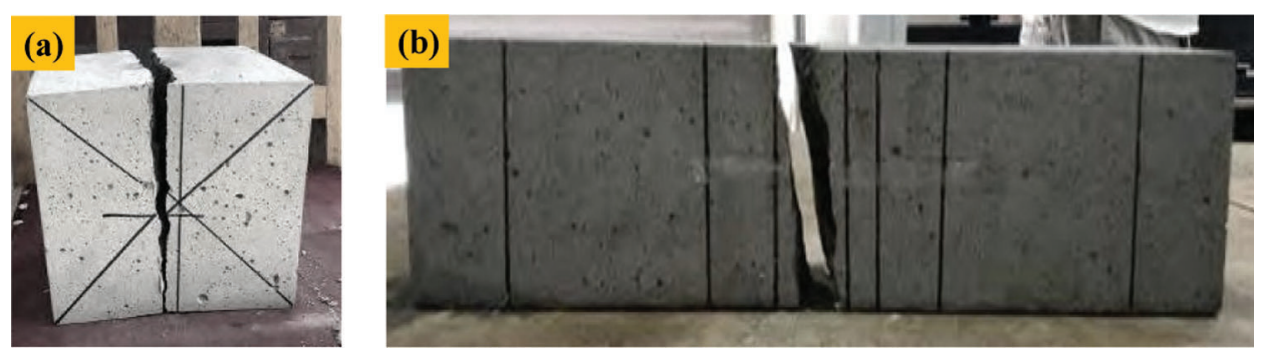

Figure 9: Typical failure mode of tensile and flexural test. (a) Splitting tensile strength; (b) Flexural strength

\section{Microscopic Properties}

Scanning electron microscopy was used to observe the microstructure of CMSCC specimens with various SP and RP content at 28-day, as shown in Fig. 10. It can be seen from Figs. 10a and 10b that the microstructure of the sample becomes denser with the increase of SP content at constant level of RP content. More granular and cluster-like slurry and hydrated calcium silicate gel (C-S-H) were produced inside the samples. C-S-H gel can fill the internal pores of samples and enhance the bonding force between aggregate and slurry, which is an important reason why the increase of SP content can improve the compressive strength and tensile strength of CMSCC.
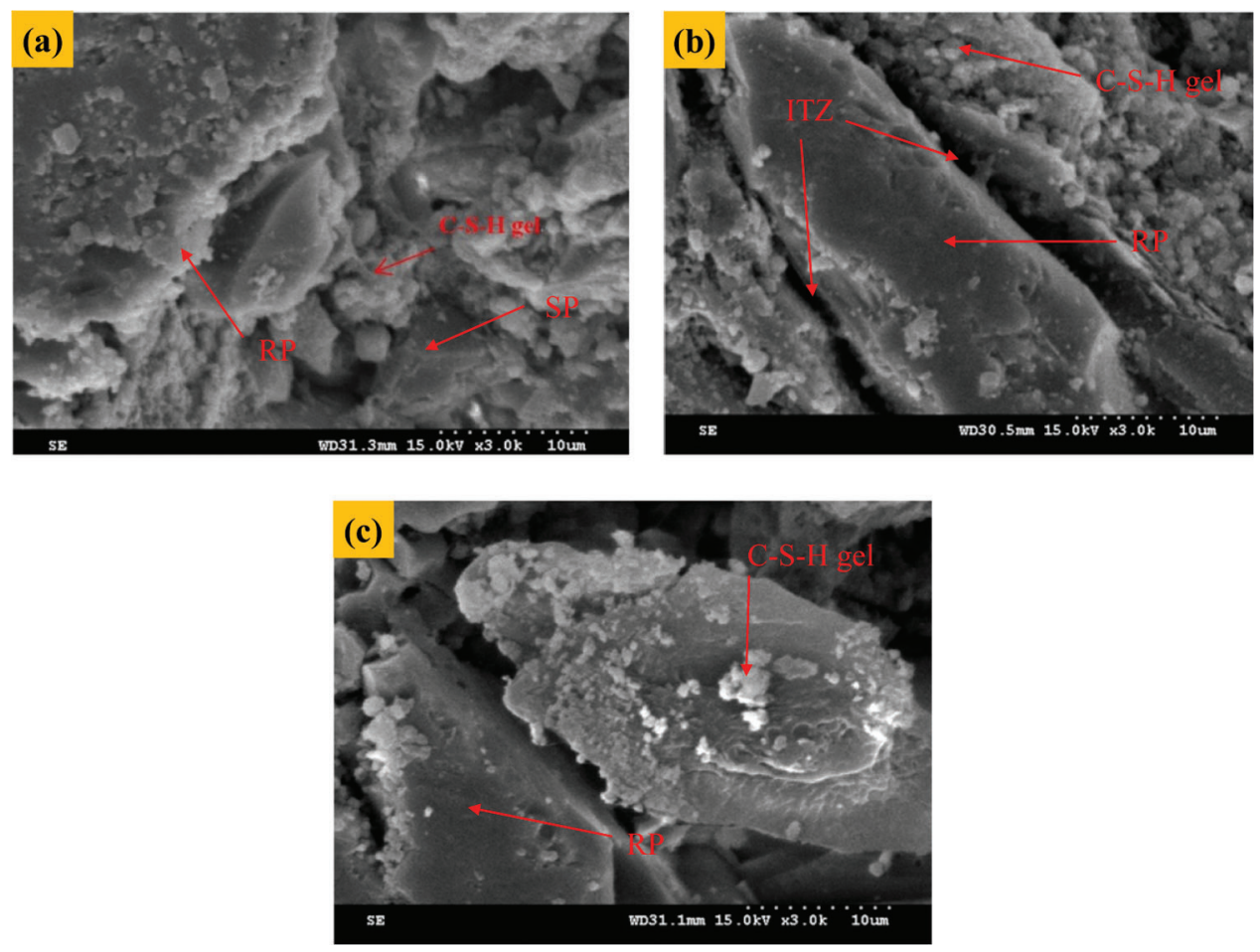

Figure 10: Microstructure of CMSCC with different SP and RP content. (a) $30 \%$ RP $+30 \%$ SP; (b) $30 \%$ RP $+10 \% \mathrm{SP}$; (c) $60 \% \mathrm{RP}+10 \% \mathrm{SP}$ 
As shown in Figs. 10b and 10c, the microstructure of the sample becomes looser with the increase of RP content at constant level of SP content. The amount of cementing materials such as cement slurry and hydrated calcium silicate gel around the aggregate decreased significantly, leading to obvious pores and weak interfacial transition zone. It is an important reason why the increase of RP content would decrease the compressive strength and tensile strength of CMSCC.

\section{Conclusions}

This study was carried out to investigate the fresh and hardened properties of CMSCC. The main conclusions as follows:

(1) SCC may be developed by replacing portion of cement and coarse aggregates by industrial waste materials, i.e., SP and RP, without compromising of workability and mechanical properties of concrete. Meanwhile, it can protect the environment and reduce the production cost.

(2) The workability, compressive strength, splitting tensile strength and flexural strength of CMSCC improves with appropriate SP and RP dosage compared to standard SCC. In order to maximize the utilization of waste materials, $20 \% \mathrm{SP}$ and $40 \% \mathrm{RP}$ can be used as the optimal ratio of the combined modifier.

(3) Combined with SEM microstructure, the addition of proper amount of SP was conducive to the formation of more and more uniform C-S-H gel. C-S-H gel could fill the internal pores of the sample and enhance the cohesive force between the aggregate. RP has a rougher surface and lower density and stiffness, which inhibits the workability and mechanical properties of CMSCC.

Data Availability: The data used to support the findings of this study are included within the article. As for the raw data of the article, we make the following explanation: (1) CMSCC mechanics data were obtained by test equipment of Sichuan Tieke New Building Materials Co., Ltd., Sichuan, China. (2) The microstructure of the materials were analyzed by means of SEM equipment in Sichuan Tieke New Building Materials Co., Ltd., Sichuan, China. We can ensure that all the data are true and reliable in the article. All the raw data can be provided in the format of Word, Excel, or PDF at any time.

Funding Statement: This research was supported by the Key Science and Technology Projects in Transportation Industry (2018-MS2-051).

Conflicts of Interest: The authors declare that they have no conflicts of interest to report regarding the present study.

\section{References}

1. Mohammed, A., Rita, N., Bassam, A. T. (2020). Properties of self-compacting high-strength concrete containing multiple use of recycled aggregate. Journal of King Saud University: Engineering Sciences, 32(2), 108-114. DOI 10.1016/j.jksues.2018.12.002.

2. Khaleel, O. R., Al-Mishhadani, S. A., Abdul Razak, H. (2011). The effect of coarse aggregate on fresh and hardened properties of self-compacting concrete (SCC). Procedia Engineering, 14, 805-813. DOI 10.1016/j. proeng.2011.07.102.

3. Ibrahim, S. A., Omar, M. O., Bassam, A. T., Bassam, A. A. (2020). Effects of using rice straw and cotton stalk ashes on the properties of lightweight self-compacting concrete. Construction and Building Materials, 235, 117541. DOI 10.1016/j.conbuildmat.2019.117541.

4. Singla, R., Kumar, S., Alex, T. C. (2019). Reactivity alteration of granulated blast furnace slag by mechanical activation for high volume usage in portland slag cement. Waste and Biomass Valorization, 1-11. DOI 10.1007/s12649-019-00580-6. 
5. Wang, X. H., Wang, K. J., Han, J. G., Taylor, P. (2015). Image analysis applications on assessing static stability and flowability of self-consolidating concrete. Cement and Concrete Composites, 62, 156-167. DOI 10.1016/j. cemconcomp.2015.05.002.

6. Wu, Q., An, X. H. (2014). Development of a mix design method for SCC based on the rheological characteristics of paste. Construction and Building Materials, 53, 642-651. DOI 10.1016/j.conbuildmat.2013.12.008.

7. Zaetang, Y., Wongsa, A., Sata, V., Chindaprasirt, P. (2015). Use of coal ash as geopolymer binder and coarse aggregate in pervious concrete. Construction and Building Materials, 96, 289-295. DOI 10.1016/j. conbuildmat.2015.08.076.

8. Feng, W. H., Liu, F., Yang, F., Li, L. J., Jing, L. et al. (2019). Experimental study on the effect of strain rates on the dynamic flexural properties of rubber concrete. Construction and Building Materials, 224, 408-419. DOI 10.1016/ j.conbuildmat.2019.07.084.

9. Mahdi, R., Mohd, R. S., Jahangir, M., Hussin, M. W., Salmiati, N. et al. (2017). Toxicity characteristics and durability of concrete containing coal ash as substitute for cement and river sand. Construction and Building Materials, 143, 234-246. DOI 10.1016/j.conbuildmat.2017.03.151.

10. Hai, R., Liu, P., Yang, Y. M., Liu, J. X. (2021). Study on mechanical properties of steel fiber reinforced fly ash selfcompacting concrete. Journal of Building Materials, 24(1), 87-92.

11. Soliman, N. A., Tagnit-Hamou, A. (2016). Development of ultrahigh-performance concrete using glass powdertowards ecofriendly concrete. Construction and Building Materials, 125, 600-612. DOI 10.1016/j. conbuildmat.2016.08.073.

12. Du, H. J., Tan, K. H. (2017). Properties of high volume glass powder concrete. Cement and Concrete Composites, 75, 22-29. DOI 10.1016/j.cemconcomp.2016.10.010.

13. Ismail, M. K., Hassan, A. A. (2016). Use of metakaolin on enhancing the mechanical properties of self-consolidating concrete containing high percentages of crumbrubber. Journal of Clean Production, 125, 282-295. DOI 10.1016/j.jclepro.2016.03.044.

14. Rahman, M. M., Usman, M., Al-Ghalib, A. A. (2012). Fundamental properties of rubber modified self-compacting concrete (RMSCC). Construction and Building Materials, 36, 630-637. DOI 10.1016/j.conbuildmat.2012.04.116.

15. Nakamura, K., Inoue, Y., Komai, T. (2021). Consideration of strength development by three-dimensional visualization of porosity distribution in coal fly ash concrete. Journal of Building Engineering, 35, 101948. DOI 10.1016/j.jobe.2020.101948.

16. Hwang, S. S., Moreno, C. C. M. (2021). Properties of mortar and pervious concrete with co-utilization of coal fly ash and waste glass powder as partial cement replacements. Construction and Building Materials, 270, 121415. DOI 10.1016/j.conbuildmat.2020.121415.

17. Eldin, N. N., Senouci, A. B. (1993). Rubber-tire particles as concrete aggregate. Journal of Materials in Civil Engineering, 5(4), 478-496. DOI 10.1061/(ASCE)0899-1561(1993)5:4(478).

18. Bompa, D. V., Elghazouli, A. Y., Xu, B., Stafford, P. J., Ruiz-Teran, A. M. (2017). Experimental assessment and constitutive modelling of rubberised concrete materials. Construction and Building Materials, 137, 246-260. DOI 10.1016/j.conbuildmat.2017.01.086.

19. Hewlett, P. C. (2018). Construction materials: Their nature and behaviour. Magazine of Concrete Research, 70(12), 648. DOI 10.1680/jmacr.18.00100.

20. Mehta, K., Monteiro, P. J. M. (2006). Concrete: Microstructure, properties, and materials, 3rd edition. Ottawa: McGraw-Hill Companies.

21. Abdallah, S. (2017). The use of waste glass as fine aggregate replacement in concrete block. Universiti Sains Malaysia.

22. Limbachiya, M. C. (2009). Bulk engineering and durability properties of washed glass sand concrete. Construction and Building Materials, 23, 1078-1083. DOI 10.1016/j.conbuildmat.2008.05.022.

23. Efnarc (2005). European guidelines for self-compacting concrete: Specification, production and use. UK.

24. ASTM C192/C192 M 16a (2016). Standard practice for making and curing concrete test specimens in the laboratory. ASTM International. 
25. ASTM C39/C39 M (2018). Standard test method for compressive strength of cylindrical concrete specimens. ASTM International.

26. ASTM C496/C496 M (2017). Standard test method for splitting tensile strength of cylindrical concrete specimens. ASTM International.

27. ASTM C78/C78 M (2018). Standard test method for flexural strength of concrete (using simple beam with third-point loading). ASTM International.

28. Boukendakdji, O., Kenai, S., Kadri, E. H. (2009). Effect of blast furnace slag on the rheology of fresh selfcompacted concrete. Construction and Building Materials, 23, 2593-2598. DOI 10.1016/j. conbuildmat.2009.02.029.

29. Boukendakdji, O., Kadri, E. H., Kenai, S. (2012). Effects of granulated blast furnace blast furnace slag and superplasticizer type on the fresh properties and compressive strength of self-compacting concrete. Cement and Concrete Composites, 34, 583-590. DOI 10.1016/j.cemconcomp.2011.08.013.

30. Dadsetan, S., Bai, J. (2017). Mechanical and microstructural properties of self-compacting concrete blended with metakaolin, ground granulated blast-furnace blast furnace slag and fly ash. Construction and Building Materials, 146, 658-667. DOI 10.1016/j.conbuildmat.2017.04.158.

31. Nazari, A., Riahi, S. (2011). The role of $\mathrm{SiO}_{2}$ nanoparticles and ground granulated blast furnace blast furnace slag admixtures on physical, thermal and mechanical properties of self-compacting concrete. Materials Science and Engineering: A, 528, 2149-2157. DOI 10.1016/j.msea.2010.11.064.

32. Mastali, M., Dalvand, A. (2016). Use of silica fume and recycled steel fibers in self-compacting concrete (SCC). Construction and Building Materials, 125, 96-209. DOI 10.1016/j.conbuildmat.2016.08.046. 